\title{
Educational intervention decreases exhaled nitric oxide in farmers with occupational
} asthma

\author{
H. Dressel*, C. Gross*, D. de la Motte*, J. Sültz ${ }^{\#}$, R.A. Jörres* and D. Nowak*
}

ABSTRACT: Allergic occupational asthma is frequent in farming populations. As educational interventions can improve disease management, the short-term effect of an educational intervention in asthmatic farmers was evaluated on the basis of spirometric indices and exhaled nitric oxide fraction ( $F$ eNO).

Farmers with occupational asthma $(n=81)$, mostly sensitised against cow dander and storage mites, participated in a 1-day educational programme. Outcome measures were assessed at baseline and after 4-6 weeks, using FeNO, lung function and a questionnaire. Results were compared with those of a control group without intervention $(n=24)$.

In the educational group, the proportion of subjects reporting work-related symptoms was reduced after the intervention. The FeNO decreased from a geometric mean of 28.2 to $25.7 \mathrm{ppb}$, and, in subjects with an elevated $(>35 \mathrm{ppb})$ baseline FeNO $(\mathrm{n}=32)$, from 59.7 to $49.2 \mathrm{ppb}$. The corresponding changes in the control group were 25.6 versus 27.7 ppb and 49.5 versus 48.1 ppb. Spirometric results were unaltered in the two groups.

Thus exhaled nitric oxide fraction, a marker of allergic airway inflammation, indicated a beneficial effect of a short-term educational intervention in farmers with occupational asthma. This suggests a potential for exhaled nitric oxide fraction in assessing the efficacy of preventive measures within a short time with higher sensitivity than spirometry.

KEYWORDS: Agriculture, educational intervention, exhaled nitric oxide, occupational asthma, respiratory symptoms, spirometry

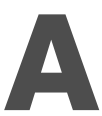
griculture is associated with a high risk of development of occupational asthma [1]. The best treatment would be complete avoidance of exposure [2], which, would often imply a change of occupation. For a variety of reasons, including economic factors, this approach is rarely feasible. As a consequence, education about technical, organisational and personal preventive measures is an important part of disease management, particularly since educational interventions are generally known to be effective in asthma treatment $[3,4]$. However, the available data in farmers seem to be limited to questionnaires as outcome measures [5-7] and do not include biomarkers of the disease.

An important biomarker of asthma is exhaled nitric oxide fraction ( $\mathrm{FeNO}$ ), which is known to be sensitive to allergen burden $[8,9]$ as well as antiinflammatory therapy $[10,11]$. Changes in FeNO, after either allergen exposure or corticosteroid treatment, occur rapidly and are detectable after a short time. It was thus hypothesised that FeNO might be suitable for the detection of a reduction in airway inflammation within a few weeks after an educational intervention in farmers with occupational asthma, in parallel to a change in respiratory symptoms.

\section{MATERIALS AND METHODS}

Farmers with occupational asthma $(n=120)$, mainly sensitised against cow dander and storage mites, took part in a 1-day educational programme organised by two German statutory accident insurance institutions for the agricultural sector at six locations in Bavaria (Germany). A total of 81 subjects (49 males (mean \pm SD age $49.8 \pm 9.1 \mathrm{yrs})$ and 32 females $(45.9 \pm 8.6 \mathrm{yrs})$ ) were included in the present study, as they were regularly working in a stable and were able to return to the same location for a second visit 4-6 weeks after the intervention. The control group comprised farmers with occupational asthma not participating in the educational programme (19 males $(44.5 \pm 10.9 \mathrm{yrs})$ and five females $(41.2 \pm 7.7 \mathrm{yrs}))$. They were visited at their farms

\section{AFFILIATIONS}

*Institute and Outpatient Clinic for Occupational and Environmental Medicine, Ludwig Maximilians University, Munich, and "Pneumology and Occupational Medicine, Neusäß, Germany.

\section{CORRESPONDENCE}

H. Dressel

Institute and Outpatient Clinic for Occupational and Environmental Medicine

Ludwig Maximilians University of Munich

Ziemssenstr. 1

D-80336 Munich

Germany

Fax: 498951603957

E-mail: holger.dressel@med.unimuenchen.de

Received

February 282007

Accepted after revision: April 172007

\section{SUPPORT STATEMENT}

This study was supported, in part, by the Bavarian statutory accident insurance institutions for the agricultural sector (LSV Niederbayern/Oberpfalz und Schwaben (Landshut and Augsburg, Germany) and LSV Franken und Oberbayern, Munich, Germany). The data represent part of the medical doctoral thesis of $\mathrm{C}$. Gross

\section{STATEMENT OF INTEREST} Statements of interest for $\mathrm{H}$. Dresse and J. Sültz can be found at www.erj.ersjournals.com/misc/ statements.shtml 
for baseline measurement and again 4-6 weeks later. All participants gave their written informed consent and the study was approved by the ethics committee of Ludwig Maximilians University (Munich, Germany).

The education, of 4-5 h duration, included two presentations by one of the authors of the present article (J. Sültz), who is a pulmonologist and occupational physician. The first presentation provided general information about the pathogenesis of asthma and allergies, environmental influences, medication and prevention. The second presentation gave details about major occupational allergens causing asthma, particularly cow dander and mites, with special focus on prevention in the workplace based on original data [12]. All major issues were illustrated by examples drawn from the patients' cases. A representative of the insurance institution added further information about technical and organisational means of allergen avoidance and demonstrated the use of personal protective equipment.

Assessments were performed in a separate room. First, FeNO was determined using a handheld device (Niox Mino ${ }^{\text {TM}}$; Aerocrine, Solna, Sweden). Afterwards, forced expiratory volume in one second and forced vital capacity were measured (SpiroPro ${ }^{\mathrm{TM}}$; Jaeger, Würzburg, Germany) following established guidelines [13] in up to eight consecutive attempts. A short interview-based questionnaire asked about the kind of animals farmed (dairy animals or swine), current symptoms at work (at least one of shortness of breath, cough with/without phlegm, wheeze and nasal irritation (yes/no)), current smoking (yes/no), medication (inhaled corticosteroids and long-acting $\beta_{2}$-agonists (yes/no)), daily working hours in the stable, use of protective personal equipment (yes/no) and usual practices in the stable.

Data are presented as proportions or means (geometric where appropriate) and corresponding SEM or SD. FeNO data were logarithmically transformed for analysis. Fisher's exact test and an unpaired t-test were used to compare groups at baseline, and McNemar's test and a paired t-test to compare values assessed before and after intervention. Significance was assumed at $\mathrm{p}<0.05$.

\section{RESULTS}

In the intervention group $(n=81), 56(69 \%)$ participants were exclusively dairy farmers, $10(12 \%)$ kept swine exclusively and $15(19 \%)$ were exposed to both dairy animals and swine or other animals. In the control group $(n=24), 20(83 \%)$ subjects were dairy farmers and four $(17 \%)$ kept both dairy animals and swine or other animals. Compared to the control group, the educational group was older $(p=0.040)$ and more often exhibited at least one current respiratory symptom at work $(p=0.007)$. Baseline FeNO did not differ significantly between the groups (table 1).

The intervention group showed a decrease in the proportion of subjects reporting at least one current respiratory symptom at work $(p=0.012$; table 1$)$, whereas the percentage of subjects wearing headgear in the stable rose $(p=0.001)$. The geometric mean FeNO decreased from 28.2 to $25.7 \mathrm{ppb}(\mathrm{p}=0.042)$. When

TABLE 1 Patient characteristics at baseline and follow-up in the intervention $(n=81)$ and control $(n=24)$ groups

\begin{tabular}{|c|c|c|c|c|}
\hline & \multicolumn{2}{|c|}{ Intervention } & \multicolumn{2}{|c|}{ Controls } \\
\hline & Baseline & Follow-up & Baseline & Follow-up \\
\hline Current symptoms at work ${ }^{\#}$ & $59(72.8)$ & $47(58.0)^{*}$ & $10(41.7)^{f}$ & $10(41.7)$ \\
\hline Daily stable working hours $h$ & $3.6 \pm 0.2$ & $3.5 \pm 0.2$ & $3.7 \pm 0.3$ & $3.8 \pm 0.3$ \\
\hline Use of protective measures & $69(85.2)$ & $71(87.7)$ & $17(70.8)$ & $17(70.8)$ \\
\hline Wash hair before going to bed & $34(42.0)$ & $31(38.3)$ & $10(41.7)$ & $13(54.2)$ \\
\hline Bedlinen changing interval weeks & $2.4 \pm 0.2$ & $2.6 \pm 0.1$ & $2.4 \pm 0.3$ & $2.4 \pm 0.3$ \\
\hline Dog inside home & $8(9.9)$ & $8(9.9)$ & $2(8.3)$ & $2(8.3)$ \\
\hline Cat inside home & $24(29.6)$ & $19(23.5)$ & $9(37.5)$ & $9(37.5)$ \\
\hline Current smoking & $1(1.2)$ & $0(0.0)$ & $0(0.0)$ & $1(4.2)$ \\
\hline Inhaled corticosteroids & $49(60.5)$ & $52(64.2)$ & $11(45.8)$ & $10(41.7)$ \\
\hline FEV $_{1}{ }^{\S} \%$ pred & $91.1 \pm 2.4$ & $93.1 \pm 2.5$ & $90.7 \pm 4.7$ & $91.4 \pm 4.4$ \\
\hline $\mathrm{FEV}_{1 / \mathrm{FVC}^{\S} \% \text { pred }}$ & $93.8 \pm 1.4$ & $94.8 \pm 1.5$ & $91.7 \pm 3.4$ & $92.4 \pm 3.1$ \\
\hline
\end{tabular}

Data are presented as $n(\%)$ or mean \pm SEM, unless otherwise indicated. FeNO: exhaled nitric oxide fraction: FVC: forced vital capacity; \% pred: \% predicted; FEV1: forced expiratory volume in one second. ${ }^{\#}$ : at least one of shortness of breath, cough with or without phlegm, wheeze and nasal irritation; ": given as geometric mean (SEM) due to data distribution; the SEM was calculated on a logarithmic scale and then antilogged; ${ }^{+}: n=32$ in intervention group and $n=10$ in control group; ${ }^{\S}: n=72$ in intervention group and $n=21$ in control group; 12 participants were unable to perform satisfactory manoeuvres at both time points. ${ }^{*}: p<0.05 ;{ }^{* *}: p<0.01$ versus baseline; $f: p<0.01$ versus intervention baseline. 


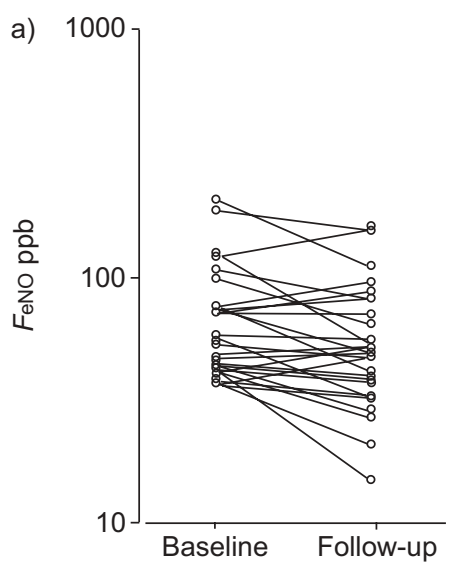

b)

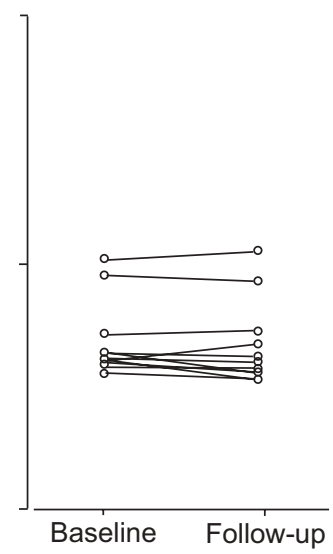

FIGURE 1. Exhaled nitric oxide fraction ( $\left.F_{\mathrm{eNO}}\right)$ at baseline and follow-up in subjects with a baseline $F_{e N O}$ of $>35 \mathrm{ppb}$ : a) intervention group ( $\mathrm{n}=32$ ); and $\mathrm{b}$ ) control group $(n=10)$.

evaluating only subjects showing a baseline FeNO of $>35 \mathrm{ppb}$ $(\mathrm{n}=32)$, FeNO decreased from 59.7 to $49.2 \mathrm{ppb}(\mathrm{p}=0.003$; fig. 1$)$. Spirometric indices did not change significantly after the intervention. In the control group, none of the outcome measures showed a significant change over time.

\section{DISCUSSION}

The present study demonstrated a significant decrease in FeNO and concomitant reduction in work-related respiratory symptoms 4-6 weeks after a 1-day educational intervention in animal farmers with occupational asthma. This improvement was not detectable by spirometry alone.

To date, only a few studies have evaluated the effects of specific education in farmers [5-7]. Based upon questionnaires, these studies revealed changes in knowledge, attitude and behaviour after the intervention. Outside occupational medicine, clinical and lung function measures, including peak flow measurements and the frequency of emergency department visits, have also been utilised in order to evaluate educational interventions $[3,4]$. Among the functional measures, FeNO appears to be particularly attractive since it reflects both the effect of allergen burden or avoidance [8, 9] and antiinflammatory effects, e.g. of corticosteroids [10, 11]. The assessment of airway hyperresponsiveness might also provide valuable information [14] but was not performed in the present study as the measurement was not feasible in the educational fieldwork setting.

Indeed, FeNO measurements have been used in large-scale epidemiological studies [15-17] and are also attracting interest in occupational medicine [18]. Currently, only a few studies have used a portable device in epidemiological fieldwork [19, 20]. No problems were encountered during measurements and the device has been demonstrated to be in acceptable agreement with a stationary nitric oxide analyser [21,22]. It should be noted that all subjects were capable of performing the FeNO manoeuvre adequately, whereas the same was not true for spirometry performed according to American Thoracic Society guidelines, despite multiple attempts. At the same time, FeNO measurement was more sensitive than spirometry. It may thus be more suitable for monitoring short-term effects related to airway inflammation, which, conversely, might have an impact upon the long-term course of the disease, as reflected in spirometry or visits to physicians. This suggests a potential role for FeNO measurement in occupational fieldwork.

In order to assess whether or not the present results were a result of the specific intervention, subjects not participating in the educational programme were included as a control group. This group did not show any changes during follow-up, particularly no decrease in FeNO, although the respective sample size was sufficient to detect a relative reduction of the same magnitude as that in the intervention group (baseline $>35 \mathrm{ppb}$ ) with a power of $>95 \%$ at a significance level of $5 \%$. The intervention group showed more respiratory symptoms than control farmers, indicating that subjects with more severe disease were more inclined to participate in the programme. This difference in disease severity was also indicated by lower proportion of subjects taking protective measures in the control group and by medication use. The control group served mainly to assess repeatability of assessments, since it was obvious that selection was unavoidable and no randomised design could be realised in the circumstances given.

Importantly, FeNO at baseline was slightly but not significantly elevated in the intervention group, whereas, after intervention, values were essentially the same in both groups. A variety of factors, including exposure, practices and medication, might have been altered by the education, but no significant changes could be traced to explain the reduction in FeNO and symptoms. This remained true in the subjects who showed a reduction in FeNO of $>10$ or $>20 \%$ after intervention $(n=41$ and 29, respectively); there were no specific characteristics that differed significantly from those of the others, probably due to various changes in several influencing factors. Exposure to swine confinement has been shown to cause an increase in FeNO in healthy nonatopic subjects [23]. Correspondingly, in the present farmers with atopic asthma, the reduction in FeNO might have been partially due to a reduction in exposure level.

There were no changes in the proportions of patients taking corticosteroids or long-acting $\beta_{2}$-adrenoceptor agonists. It was not possible to collect reliable data on medication intake by objective means, such as inhalation counters. While talking with the farmers, however, it became apparent that a considerable number took their medication irregularly. The intervention might have favoured more regular steroid use, contributing to the decrease in FeNO. Irrespective of the differences between the groups and the unresolved issues regarding causative factors, it appears to be safe to derive as a message of the present study that FeNO measurement was capable of demonstrating an effect of specific education within a short time using easy-to-perform measurements. The type of evaluation performed in farmers might also be suitable in other occupations involving work-related asthma.

In conclusion, the exhaled nitric oxide fraction showed a significant short-term reduction after an educational intervention in animal farmers with workplace-related allergic asthma, indicating a success of the education. Thus exhaled nitric oxide fraction has potential in the fast evaluation and, possibly, optimisation of nonpharmacological interventions in patients with occupational asthma. 


\section{ACKNOWLEDGEMENTS}

The authors would like to thank J. Kellberger for support in data processing.

\section{REFERENCES}

1 Kogevinas M, Anto JM, Sunyer J, Tobias A, Burney P. Occupational asthma in Europe and other industrialised areas: a population-based study. European Community Respiratory Health Survey Study Group. Lancet 1999; 353: 1750-1754.

2 Nicholson PJ, Cullinan P, Newman Taylor AJ, Burge PS, Boyle C. Evidence based guidelines for the prevention, identification, and management of occupational asthma. Occup Environ Med 2005; 62: 290-299.

3 Gibson PG, Powell H, Coughlan J, et al. Self-management education and regular practitioner review for adults with asthma. Cochrane Database Syst Rev 2003; 3: CD001117.

4 Guevara JP, Wolf FM, Grum CM, Clark NM. Effects of educational interventions for self management of asthma in children and adolescents: systematic review and metaanalysis. BMJ 2003; 326: 1308-1311.

5 Ferguson KJ, Scharf T. Intervention research in agriculture: examples from the swine confinement and respiratory health project. Am J Ind Med 1996; 29: 386-391.

6 Ferguson KJ, Gjerde CL, Mutel C, et al. An educational intervention program for prevention of occupational illness in agricultural workers. J Rural Health 1989; 5: 33-47.

7 Gjerde C, Ferguson KJ, Mutel C, Donham KJ, Merchant J. Results of an educational intervention to improve the health knowledge, attitudes and self-reported behaviors of swine confinement workers. J Rural Health 1991; 7: 278-286.

8 Beraldi E, Carra S, Dario C, et al. Effect of natural grass pollen exposure on exhaled nitric oxide in asthmatic children. Am J Respir Crit Care Med 1999; 159: 262-266.

9 Peroni DG, Piacentini GL, Costella S, et al. Mite avoidance can reduce air trapping and airway inflammation in allergic asthmatic children. Clin Exp Allergy 2002; 32: 850-855.

10 Kharitonov SA, Barnes PJ. Exhaled biomarkers. Chest 2006; 130: 1541-1546.

11 Taylor DR, Pijnenburg MW, Smith AD, De Jongste JC. Exhaled nitric oxide measurements: clinical application and interpretation. Thorax 2006; 61: 817-827.
12 Berger I, Schierl R, Ochmann U, Egger U, Scharrer E, Nowak D. Concentrations of dust, allergens and endotoxin in stables, living rooms and mattresses from cattle farmers in southern Bavaria. Ann Agric Environ Med 2005; 12: 101-107.

13 Miller MR, Hankinson J, Brusasco V, et al. Standardisation of spirometry. Eur Respir J 2005; 26: 319-338.

14 Gronke L, Kannies F, Holz O, Jörres RA, Magnussen H. The relationship between airway hyper-responsiveness, markers of inflammation and lung function depends on the duration of the asthmatic disease. Clin Exp Allergy 2002; 32: 57-63.

15 Nordvall SK, Janson C, Kalm-Stephens P, Foucard T, Toren K, Alving K. Exhaled nitric oxide in a populationbased study of asthma and allergy in childhood. Allergy 2005; 60: 469-475.

16 Jouaville LF, Annesi-Maesano I, Nguyen LT, Bocage AS, Bedu M, Caillaud D. Interrelationships among asthma, atopy, rhinitis and exhaled nitric oxide in a populationbased sample of children. Clin Exp Allergy 2003; 33: 1506-1511.

17 Henriksen AH, Lingaas-Holmen T, Sue-Chu M, Bjermer L. Combined use of exhaled nitric oxide and airway hyperresponsiveness in characterizing asthma in a large population survey. Eur Respir J 2000; 15: 849-855.

18 Campo P, Lummus ZL, Bernstein DI. Advances in methods used in evaluation of occupational asthma. Curr Opin Pulm Med 2004; 10: 142-146.

19 Pijnenburg MW, Floor SE, Hop WC, De Jongste JC. Daily ambulatory exhaled nitric oxide measurements in asthma. Pediatr Allergy Immunol 2006; 17: 189-193.

20 Vahlkvist S, Sinding M, Skamstrup K, Bisgaard H. Daily home measurements of exhaled nitric oxide in asthmatic children during natural birch pollen exposure. J Allergy Clin Immunol 2006; 117: 1272-1276.

21 Alving K, Janson C, Nordvall L. Performance of a new hand-held device for exhaled nitric oxide measurement in adults and children. Respir Res 2006; 7: 67.

22 McGill C, Malik G, Turner SW. Validation of a hand-held exhaled nitric oxide analyzer for use in children. Pediatr Pulmonol 2006; 41: 1053-1057.

23 Sundblad BM, Larsson BM, Palmberg L, Larsson K. Exhaled nitric oxide and bronchial responsiveness in healthy subjects exposed to organic dust. Eur Respir J 2002; 20: 426-431. 